\title{
Erratum to: Zircon-scale insights into the history of a Supervolcano, Bishop Tuff, Long Valley, California, with implications for the Ti-in-zircon geothermometer
}

\author{
Mary R. Reid $\cdot$ Jorge A. Vazquez $\cdot$ Axel K. Schmitt
}

Published online: 28 August 2010

(C) Springer-Verlag 2010

\section{Erratum to: Contrib Mineral Petrol DOI: 10.1007/s00410-010-0532-0}

Unfortunately, several errors related to the figure captions are detected in the original version of the online published article.

The figure caption in Fig. 1 mentions that the symbols are color-coded in the same way as symbols in Figs. 3, 4, and 7, but this should read Figs. 3, 4, and 8 instead. The correct Fig. 1 caption is given below.

Fig. 1 Location map for the Bishop Tuff in eastern California, USA. Stratigraphic columns show sequences of fall $(F)$ and ignimbrites $(I g)$ in the eastern and northern Bishop Tuff recognized by Wilson and Hildreth (1997). Relative stratigraphic positions of the samples studied here

The online version of the original article can be found under doi:10.1007/s00410-010-0532-0.

M. R. Reid $(\bowtie)$

School of Earth Sciences and Environmental Sustainability, Northern Arizona University, Flagstaff, AZ 86011-4099, USA e-mail: mary.reid@nau.edu

\section{J. A. Vazquez}

Department of Geological Sciences, California State University, Northridge, Los Angeles, CA 91330-8266, USA

Present Address:

J. A. Vazquez

United States Geological Survey, 345 Middlefield Road,

Mail Stop 910, Menlo Park, CA 94025, USA

\section{A. K. Schmitt}

Department of Earth and Space Sciences,

University of California, Los Angeles, CA 90095-1567, USA are indicated with units color-coded in the same way as symbols in Figs. 3, 4, and 8. Representative temperatures are shown in Fig. 3. Modified after Wilson and Hildreth (1997) and Hildreth and Wilson (2007).

The figure notations in Fig. 3 show the symbols reversed than what they are intended to be (the figure caption is however correct). The correct version of Fig. 3 is given below.

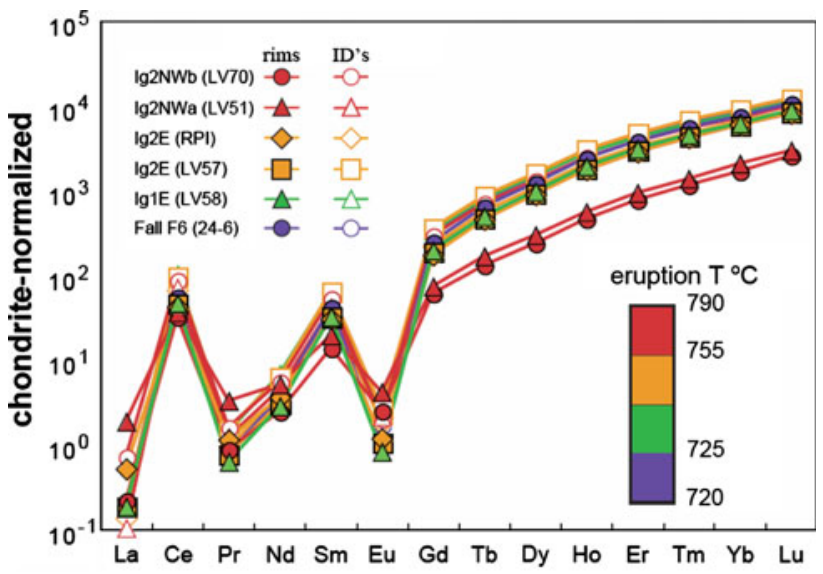

Fig. 3 Chondrite-normalized REE diagram for zircon rims (solid symbols) and intermediate domains (open symbols) within Bishop Tuff zircons showing median values for zircons from each sample. Intermediate domains have concentrations that are similar to somewhat greater than higher concentration zircons rims. Symbols and colors are explained in the legend, are keyed to general eruption temperatures based on FeTi-oxide geothermometry (Hildreth and Wilson 2007 and references therein), and are correlated with stratigraphic units as defined by Wilson and Hildreth (1997). Eruption temperatures are approximate, especially because there is significant overlap in estimated temperatures between individual pumices from the $\operatorname{Ig} 1 \mathrm{E}$ and $\operatorname{Ig} 2 \mathrm{E}$ and because they could, moreover, be $\sim 20^{\circ} \mathrm{C}$ lower (Ghiorso and Evans 2008) 
The figure caption in Fig. 4 mentions that the colors are keyed to eruption sequence as in Fig. 4, but this should read Fig. 3 instead. In addition, the dashed lines in the figures should have been identified as enclosing compositional ranges obtained for the "BT mount" from the Watson et al. (2006) study. The correct Fig. 4 caption is given below.

Fig. 4 Covariations between a Ti, b Eu/Eu*, c Nd/Yb, and $\mathbf{d} \mathrm{Sm}$ with $\mathrm{Zr} / \mathrm{Hf}$. Dashed lines enclose the compositional ranges obtained in this study on the "BT mount" from the Watson et al. (2006) study (see text for details). A typical $1 \mathrm{SD}$ uncertainty in $\mathrm{Ti}$ content is illustrated. Labeled arrows suggest processes that could account for the observed covariations (xl. = crystallization) with "?" symbols indicating processes in addition to zircon fractionation, which decreases $\mathrm{Zr} / \mathrm{Hf}$. Relationship of Sm to $\mathrm{Zr} / \mathrm{Hf}$ is typical of that of the $\mathrm{Y}+\mathrm{REE}$ with respect to $\mathrm{Zr} / \mathrm{Hf}$ with the caveats that in the IDs; Ce defines a more pronounced negative trend, and the $\mathrm{Y}+\mathrm{HREE}$ tend to cluster at concentrations similar to somewhat higher than those of the rims. Rims: solid symbols; IDs: open symbols. Colors keyed to eruption sequence as in Fig. 3.

The figure caption in Fig. 8 mentions that the symbols are the same as those in Fig. 5. It should read Fig. 3 instead. The correct Fig. 8 caption is given below.

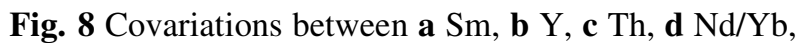
e $\mathrm{Zr} / \mathrm{Hf}$, and $\mathbf{f} \Delta \mathrm{Ti}$ with $\sum \mathrm{REE}^{3+}: P$ in excess of that expected for ideal xenotime $\left(\left(\mathrm{Y}, \mathrm{REE}^{3+}\right) \mathrm{PO}_{4}\right)$ substitution (i.e., molar $\left.\left[\left(\mathrm{Y}, \mathrm{REE}^{3+}\right): \mathrm{P}\right]-1\right)$. Delta Ti is the deviation in $\mathrm{Ti}$ for a given $\mathrm{Zr} / \mathrm{Hf}$ from that expected from the linear $\mathrm{Ti}-\mathrm{Zr} / \mathrm{Hf}$ covariation defined by zircon rims $(\sim 80 \%$ of rims are within analytical uncertainty at 2 SD of this correlation, and we treat this trend as a "normal" liquid line of descent). Symbols as in Fig. 3 except that those that are dashed are IDs for which anomalously high Ti was independently suspected on the basis of apparently anomalously high Fe. See text for additional details. 